their danger was indeed Ellul's purpose in writing the book: had he considered more deeply Bavink's emphasis on the element in technology of fitness for a purpose he might have written a less pessimistic and a more con. structive book.

R. Brightman

\section{INTERNATIONAL ENCYCLOPEDIA OF SCIENCE}

The International Encyclopedia of Science

Edited by James R. Newman. Vol. 1: A to D. Pp. ix + 1-342 + plates 1-26. Vol. 2: E to L. Pp. v+343-688+ plates 27-49. Vol. 3: M to R. Pp. v+689-1034+plates 50-70. Vol. 4: S to Z. Pp. $v+1035-1379+$ plates $71-84$. (Edinburgh and London: Thomas Nelson and Sons, Ltd., 1965.) 252s. the set.

THE International Encyclopedia of Science is a hand. L some work of four large volumes, totalling nearly 1,400 pages. It is produced in first-rate American style with excellent printing, colour diagrams and photographs and many other illustrations in colour. It was first published in the United States as The Harper Encyclopedia of Science in 1963, and now appears, with some additional material, printed in Edinburgh with the original American spelling. At 3 guineas per volume, the price of this valuable work cannot be considered excessive.

Four hundred and fifty scientists and engineers have contributed nearly 4,000 articles which appear in the work. An encyclopaedia, almost like an anthology, is a work of compromise, selection, preference and taste. There are bound to be space limitations no matter how large the project. One may say of the work, like Samuel Johnson of his Dictionary, "In this work when it shall be found that much is omitted, let it not be forgotten that much likewiso is performed".

The scope of the work is wide and includes all the so-called pure and applicd sciences. The mathematics sections are particularly full, even to the extent of some overlapping with one another, when separate authorities write the articlos in which there is some common material.

The standard of difficulty of the Encyclopedia varies from subject to subject: gencrally it is of undergraduate level or less, and much of it would appeal to the sixthformer. The intelligent layman and woman will find these volumes admirable as bodside books, although some of the mathematics, albeit logically set out, is not easy and often is of greater difficulty than the rest.

In so large and comprehensive a work, it would be easy and priggish to make criticisms in detail. There is a sizeable article on quaternions, but, of a class of thirty mathematies graduates in one British university, only one knew what they were, and even he could not suggest any applications of them-nor indeed does the Encyclopedia.

There is no article on the laser and evon the paragraph on the maser does not give a worthy explanation of its action.

In the statistics section, average family income is given as that of the median family in the income hierarchy, and this would be true only if incomes were distributed normally or symmetrically.

More might have been said about entropy and degrees of freedom, both of which have wide applications in the sciences.

Acousties is dealt with as the physics of sound and not the science of hearing, although there is a separate article on sound. Some of this is rather old-fashioncd in concoption; for example, the idea that harmonics define a tone quality.

There is an article on $\pi$ which mentions its irrational but not its transcendental nature, though this is not forgotten in the article on ' $e$ '. Chemical research is the subject of an article which overlaps with other chemical entries, but there is no article on physical research. In an American publication, it is delightful to find that the American gentleman of foriune, "Rumford, Benjamin Thompson, Count", is described as a British physicist, as indeed he was, among other things ! The pituitary body (an endocrine gland) is given an article, but there is no mention of its other name, 'hypophysis'. Lindberg is incorrectly given as the first man to fly the Atlantic.

Although one may feel sorry for writers and compilers of scientific encylopaedias, since much of their work becomes of historic interest only, because of the rapid progress of the subject, there is much in these volumes which will not quickly become effete. Moreover, it can be expected that another edition will be called for very quickly, because of the scope and worthiness of the present work. In this case, a 'tidying up' of the Encyclopedia will produce an even better set of books. Large as are these four volumes, 1,400 pages are a not great amount of space to encompass, even briefly, the whole of scientific knowledge. Some of the articles, such as those which deal with pure mathematics, statistics and quantum theories, should be read by future editors, so that common material between the parts of these (and other) subjects respectively might be eliminated. Some of the smaller articles could be combined into larger treatments of the subjects and references made thereto under the present headings. This would save space for more comprehensive essays on some important topics about which little appears in the present volumes.

The many pages of tabulated information, the bibliographies and the index are excellent. The whole is generally a splendid piece of work. W. L. Sumner

\section{INSECT NERVOUS SYSTEM}

The Physiology of the Insect Central Nervous System Edited by J. E. Treherne and J. W. L. Beament. (Papers from the 12th International Congress of Entomology held in London, 1964.) Pp. ix + 277. (London: Academic Press, Inc. (London), Ltd.; New York: Academic Press, Inc., 1965.) $60 s$.

THE Physiology of the Insect Central Nervous System is a collection of fifteen articles based on papers presented at the twelfth International Congress of Entomology, and it is not surprising that it is a mixed bag, ranging from original contributions of interest mainly to the neurophysiologist, to reviews of recent work which are of interest to the general reader. It includes the following topics: properties of the axon (Narahashi); composition of the fluid bathing the neurones (Treherne); ultrastructure of synapses (Smith); free amino-acids of the central nervous system (Ray); neurophysiological mapping and pharmacological study of a ganglion (Bernard, Gahery, Callec and Boistel); co-ordination of reflex activities (Weevers, Wilson, Miller and Rowell); neuronal pathways (Hughes); recordings from single neurones of optic lobe and brain (Horridge, Scholes, Shaw and Tinstall); learning in headless insects (Hoyle); and stimulation of areas in the brain concerned with control of sound production (Huber).

The articles by Narahashi and Troherne review their own recent work on the norve impulse and show that the insect has fluid of an ionic composition differing from that of haemolymph bathing the axon and that the nerveimpulse follows the classical pattern. Smith points out that axons which are closely apposed may have no glial material between their membranes, and he regards this situation as a pre-requisite for a synapse. It is of interest to speculate on the possible function of such presumptive synapses which are found in both contral and peripheral systems. In his review of neuronal pathways, Hughes gives in a concise form an excellent account of method- 